\title{
Evaluation of bovine luteal blood flow by using color Doppler Ultrasonography
}

\author{
Lüttgenau, J ; Bollwein, H
}

\begin{abstract}
Since luteal vascularization plays a decisive role for the function of the corpus luteum (CL), the investigation of luteal blood flow (LBF) might give valuable information about the physiology and pathophysiology of the CL. To quantify LBF, usually Power mode color Doppler ultrasonography is used. This method detects the number of red blood cells moving through the vessels and shows them as color pixels on the B-mode image of the CL. The area of color pixels is measured with computer-assisted image analysis software and is used as a semiquantitative parameter for the assessment of LBF. Although Power mode is superior for the evaluation of LBF compared to conventional color Doppler ultrasonography, which detects the velocity of blood cells, it is still not sufficiently sensitive to detect the blood flow in the small vessels in the center of the bovine CL. Therefore, blood flow can only be measured in the bigger luteal vessels in the outer edge of the CL. Color Doppler ultrasonographic studies of the bovine estrous cycle have shown that plasma progesterone (P4) concentration can be more reliably predicted by LBF than by luteal size (LS), especially during the CL regression. During the midluteal phase, cows with low P4 level showed smaller CL, but LBF, related to LS, did not differ between cows with low and high P4 levels. In contrast to non-pregnant cows, a significant rise in LBF was observed three weeks after insemination in pregnant cows. However, LBF was not useful for an early pregnancy diagnosis due to high LBF variation among cows. When the effects of an acute systemic inflammation and exogenous hormones on the CL are examined, the LBF determination is more sensitive than LS assessment. In conclusion, color Doppler ultrasonography of the bovine CL provides additional information on luteal function compared to measurements of LS and plasma P4, but its value as a parameter concerning assessment of fertility in cows has to be clarified.
\end{abstract}

DOI: https://doi.org/10.1016/j.repbio.2014.03.003

Posted at the Zurich Open Repository and Archive, University of Zurich

ZORA URL: https://doi.org/10.5167/uzh-107137

Journal Article

Supplemental Material

Originally published at:

Lüttgenau, J; Bollwein, H (2014). Evaluation of bovine luteal blood flow by using color Doppler Ultrasonography. Reproductive Biology, 14(1):103-109.

DOI: https://doi.org/10.1016/j.repbio.2014.03.003 

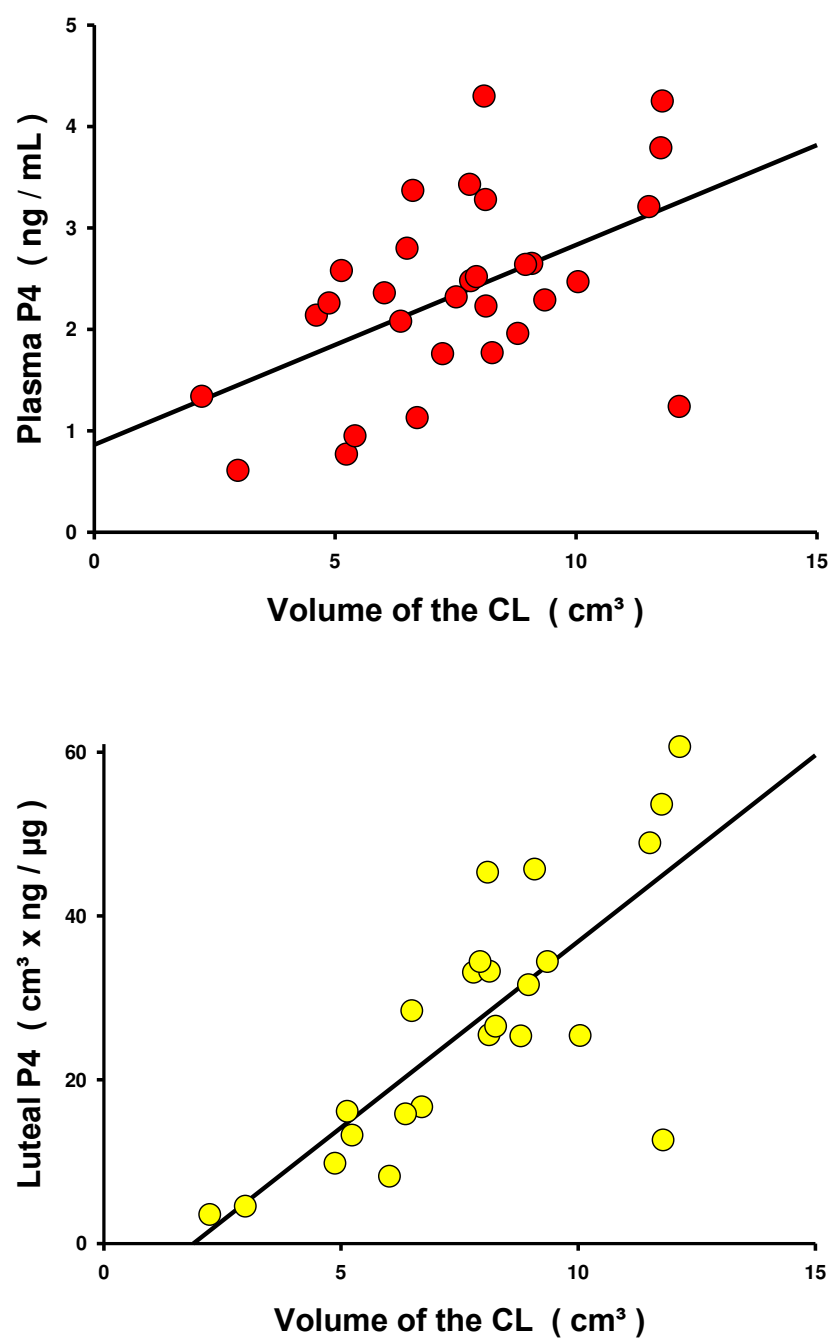